\title{
Persistence of Healthcare-Associated (Nosocomial) Infections Due to Inadequate Hand Hygiene: Part 2-Human Factors
}

\author{
Robert B. Raffa ${ }^{1,2,3}$, Joseph V. Pergolizzi ${ }^{3,4}$, Robert Taylor ${ }^{4}$, Sanjib Choudhuri'5, Robert Rodenbeck ${ }^{5}$ \\ ${ }^{1}$ University of Arizona College of Pharmacy, Tucson, AZ, USA \\ ${ }^{2}$ Professor Emeritus, Temple University School of Pharmacy, Philadelphia, PA, USA \\ ${ }^{3}$ Neumentum, Inc., Palo Alto, CA, USA \\ ${ }^{4}$ NEMA Research, Inc., Naples, FL, USA \\ ${ }^{5}$ Delta Faucet Co., Indianapolis, IN, USA \\ Email: robert.raffa@temple.edu
}

How to cite this paper: Raffa, R.B., Pergolizzi, J.V., Taylor, R., Choudhuri, S. and Rodenbeck, R. (2018) Persistence of Healthcare-Associated (Nosocomial) Infections Due to Inadequate Hand Hygiene: Part 2-Human Factors. Pharmacology \& Pharmacy, 9, 310-323.

https://doi.org/10.4236/pp.2018.98024

Received: June 27, 2018

Accepted: August 7, 2018

Published: August 10, 2018

Copyright $\odot 2018$ by authors and Scientific Research Publishing Inc. This work is licensed under the Creative Commons Attribution International License (CC BY 4.0).

http://creativecommons.org/licenses/by/4.0/

\begin{abstract}
A healthcare-associated infection (defined as an infection acquired within a healthcare facility), such as due to transmission via medical equipment or by healthcare providers is the most frequent adverse event in the healthcare delivery system. But why does the problem persist, when infection control measures are known, simple, and low-cost? We reviewed some biologicaland treatment-factors in Part 1, and we now review some human-factors. Healthcare-associated infections are a major public health problem even in advanced healthcare systems. They affect hundreds of millions of patients each year, and are responsible for increased morbidity, mortality, and financial burden. This is perplexing, since good-hygiene practices are known and promoted. Disinfection, sterilization, handwashing, and alcohol rubs should be more effective, but human-factors interfere. The persistent high prevalence of nosocomial infections, despite known hygienic practices, is attributable to two categories of factors: biological and inherent shortcomings of some practices (considered in Part 1), and human factors (considered here). A new approach is considered in Part 3.
\end{abstract}

\section{Keywords}

Infection, Nosocomial, Hospital, Healthcare-Associated, Hygiene, Handwashing

\section{Introduction}

Recognition of the problem of healthcare-associated infection (an infection that 
is acquired in a healthcare setting-i.e., not related to the original illness and not present or incubating at the time of admission to the healthcare facility) [1] [2] [3] and efforts to address the problem date back nearly 200 years [4]. Yet despite governmental-agency and professional-organization guidelines, codes, and standards that are directed at eliminating the problem [4], the prevalence of healthcare-associated infection (HAI) is estimated to remain as much as $12 \%$ in developed countries and as much as $20 \%$ in low- and middle-income countries, which translates into hundreds of millions of affected people worldwide [5] [6] [7] [8].

Since the problem of HAI is widely-recognized and infection control measures are widely-known, simple, and low-cost, there is an apparent disconnect between guidance and practice. Therefore, we sought to examine the question of why the prevalence of HAI, although lower than historical levels, remains unacceptably high. We identified two general sets of factors. The first involves biological-centric factors (e.g., resistant nosocomial strains) and treatment-centric factors (e.g., lack of antimicrobial efficacy of soap) - which we reviewed in Part 1 [9]. The second involves human-centric factors (e.g., lack of training, inconvenience, negative outcomes, etc.), which we review here.

\section{The Persistence of HAI}

HAIs are the most frequent adverse events associated with the delivery of routine and emergency healthcare [2]. They result via transmission by healthcare personnel and devices and procedures used to treat patients and to help them recover, and the physical equipment of the facility itself. Examples include surgical site infections (SSIs), catheter-associated urinary tract infections (CAUTIs), central line-associated bloodstream infections (CLABSIs), and ventilator-associated pneumonia (VAP), among others [3]. According to estimates by the World Health Organization (WHO) [5], approximately $30 \%$ of ICU (intensive care unit) patients in high-income countries are affected by at least one HAI, and the frequency in middle- and low-income countries is double or triple that number. European epidemiological surveys estimate that HAIs are responsible for about 16 million extra-days of hospital stay and about 150,000 deaths annually $(37,000$ directly-attributable and an additional 110,000 contributory) [6]. An estimated nearly 100,000 deaths per year in the United States are attributed to HAI [8]. Annual financial losses attributable to HAI in the United States are estimated to be nearly $\$ 20$ billion in direct hospital costs, and $\$ 28$ - 45 billion overall [10].

\section{Hands as Source of Pathogen Transmission}

Transmission of HAI by hands involves the following sequence of events [4]:

1) A pathogenic organism must be present at the original host site (on a patient or surface).

2) The pathogenic organism must remain viable at the original host site until transmission. 
3) The barrier to transmission must be inadequate or omitted (defective glove, incomplete hand washing, ineffective hand hygiene agent, etc.).

4) The pathogen must be transmitted to a recipient or to an intermediate host location.

Interruption of any step in this process disrupts transmission, whereas failure to interrupt a step allows transmission. The need for assiduous surveillance is highlighted by the fact that although the source of pathogenic organisms is sometimes obvious (e.g., infected or draining wounds), but not always (e.g., the large volume of skin normally shed daily deposits millions of viable microorganisms to surfaces such as gowns, bedding, etc., particularly staphylococci and enterococci, which are resistant to desiccation) and to healthcare personnel (e.g., Klebsiella spp.) while performing even seemingly "clean" activities like lifting a patient, taking vital signs, or therapeutic touch [11]. Handwashing can play a critical role in interrupting the HAI transmission sequence [12] [13].

\section{Handwashing as a Measure to Avoid HAIs}

Boyce and Pittet [4] have critically reviewed the pros and cons of various procedures used for hand hygiene, which are succinctly summarized below.

\subsection{Soap(s) and Water}

Soaps and detergent-based products "clean" hands primarily by the physical action of removing contaminated solids such as dirt and organic substances. Therefore, the cleaning activity of these substances (which mostly contain esterified fatty acids and sodium or potassium hydroxide) remove flora that are loosely adherent on the hands or are transient. Because of this mechanism, it is reasonable that longer wash times are superior to shorter wash times. However, plain soaps (viz., non-antimicrobial products) have little, if any, antimicrobial activity beyond the action of physical removal of pathogens. Studies have shown that handwashing with plain soap fails to remove pathogens from the hands of hospital personnel [14] and plain soaps can themselves become contaminated and increase bacterial counts on skin [15].

\subsection{Alcohol-Based Antiseptics (Sanitizing Rinses, Rubs, Gels, Foams)}

Alcohols denature proteins by disrupting existing intramolecular hydrogen bonds of protein side chains and forming new hydrogen bonds between the alcohol molecule and the amino acid side chains of the protein [16]. Since these reactions require the presence of water, most commercial products are a mixture of alcohol and water. Alcohols are effective against a wide variety of gram-positive and gram-negative bacteria, fungi, and viruses (mostly enveloped strains). Thus, the use of alcohol-based products is germicidal (assuming the skin not blocked by dirt or other material) and reduces bacterial counts to a greater extent than does washing with plain soap or antimicrobial soap [14]. As a consequence, al- 
cohol is more effective in preventing HAI. However, if alcohol-impregnated products do not contain enough alcohol, then they are no more effective than is soap and water [17] [18].

\section{Handwashing: Positive Aspects}

Several studies through the years have documented the now universally accepted fact that hand hygiene is an effective measure in reducing HAIs. In any early study, Mortimer et al. (1962) [19] found that $92 \%$ of the infants handled in the nursery by nurses with unwashed hands acquired the strain of an infant carrier, compared to only $53 \%$ of the infants that were handled by nurses who washed their hands. Larson (1988) [20] reviewed the literature on handwashing published from 1879 through 1986 (423 articles). Using established criteria, the conclusion was that there is a causal link between handwashing and risk of infection. This was extended by Larson (1999) [21], who reviewed the published research and found a causal link between hand hygiene and spread of nosocomial infections. Interestingly, some negative aspects of frequent conventional (soap or detergent) handwashing were highlighted, including skin damage and increased risk of pathogen transmission. Some of the recommendations included the greater use of alcohol-based products rather than detergent-based products, and the incorporation of moisturizers in the formulations. Additional studies during the 1990s confirmed that handwashing by the staff led to a measurable positive reduction of nosocomial infection rates [22] [23] [24]. The positive evidence was reinforced by Allegranzi and Pittet (2009) [25], who tabulated the more than 20 hospital-based studies conducted between 1977 and 2008 that examined the impact of hand hygiene on the risk of HAI, and found a strong correlation between improved hand hygiene practices and reduced infection and cross-transmission (HAI) rates. The same was found in a recent review of hand hygiene in nursing homes [26].

Based on these studies and others, it is now the collective wisdom that good hand hygiene is a primary means to mitigate the spread of healthcare-associated infections. Then why does the problem of HAI still persist? We reviewed some of the technical explanations in Part 1; [9] some human factors (below) are equally, or more, important.

\section{The Problem of Poor Compliance}

Larson et al. (2000) [27] state succinctly: “... the handwashing behavior of healthcare professionals-has proved to be stubbornly resistant to intervention and change". They cite poor compliance to standards for handwashing practice (in quality and duration) among physicians and nurses, with rates of only $20 \%$ $80 \%$ [28] [29] [30]. Only two of the 15 prior studies reported any success of various educational strategies, performance feedback, or environmental controls or modifications in bringing about sustained behavioral change or improvement in rates of infection [31]. Likewise, Allegranzi and Pittet (2009) [25] in the review 
cited above that summarized the strong evidence for the positive effects of good hand hygiene, report the disappointing finding that among all of the reviewed studies, the increased rate of compliance at follow-up never exceeded $81 \%$. Kingston et al. (2016) [32] reviewed the literature on hand hygiene compliance published after 2009 (following publication of the WHO hand hygiene guidelines) and concluded that hand hygiene improvement strategies result in "... moderate improvements in hand hygiene compliance". Of the studies that reported both pre- and post-intervention data, the mean baseline compliance rate was found to be only $34 \%$ before intervention, and improved to a mean of only $57 \%$ after intervention. A plot of their results reveals a consistent percent increase in compliance (mean $=23 \%$ ) rather than an attainment of high-compliance rates (Figure 1). In their extensive review, Boyce and Pittet (2002) [4] report marked differences in handwashing in different hospitals (ranging from an average of 5 to 30 times per shift) and different wards within the hospital (e.g., an average of 8 handwashings per hour in pediatric care to 20 per hour for intensive care units).

Allegranzi and Pittet (2009) [25] summarize the current situation that "... the goal of sustained $100 \%$ compliance appears unlikely to be achieved because of the complex range of factors influencing [healthcare workers] behaviour related to hand hygiene performance". We consider some of the hurdles impeding improvement next.

\section{Handwashing: Negative Aspects}

Frequent and repeated use of handwashing products can lead to dry skin, irritation, and even more serious problems such as chronic contact dermatitis [33]. This is particularly true for products that contain soaps and other detergents, but is also true for products that contain alcohol. One survey of nursing staff found

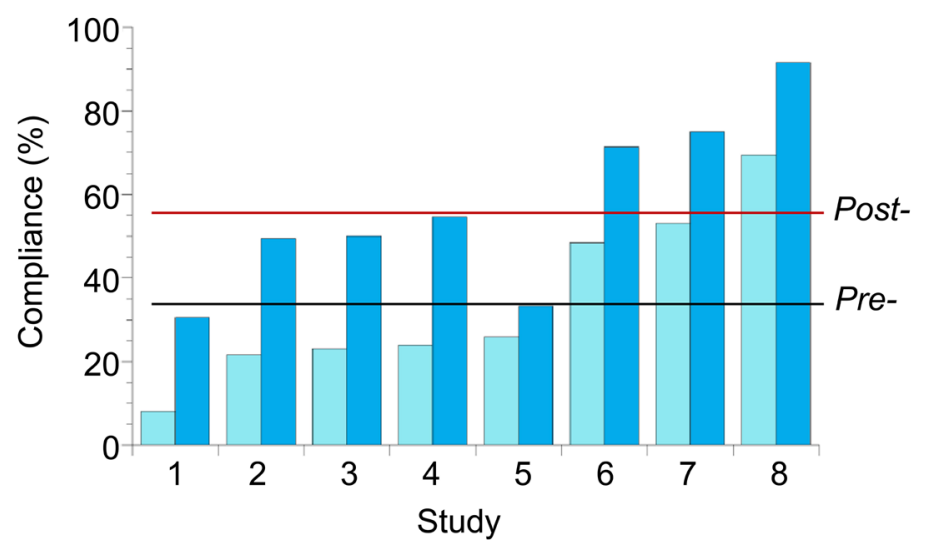

Figure 1. The effect of intervention on hand-hygiene compliance reported in 8 studies published between December 2009 and February 2014. The pre-intervention compliance values are the leftmost column for each study; the post-intervention values are the rightmost column for each study. The mean pre- and post-intervention values are shown by the horizontal lines. The figure was created from tabular data from studies reported in Kingston et al. (2016) [32] (referenced therein), with permission. 
that almost $90 \%$ experience some washing-related skin problem, and that an estimated $25 \%$ have symptoms or signs of dermatitis involving their hands [33]. The cause of the irritation can be the antimicrobial agent itself, or one or more component of the formulation. Confounding the problem, detergents and alcohols can damage skin by the same mechanism as their antimicrobial action, viz., denaturation of proteins. Although the degree of irritation can be reduced by addition of emollients and humectants to the formulations [34], it is not eliminated. Affected healthcare providers experience skin that feels rough, dry, and burning, with erythema (reddening), scaling, and fissures. In addition to being unsightly and uncomfortable, damaged skin can host flora that are not normally present to the same extent in healthy skin (e.g., staphylococci and gram-negative bacilli) [35] [36].

The use of iodophors, chlorine compounds, or related products alone or in combination can cause contact dermatitis, which is exacerbated by warm water, low relative humidity, failure to use counter measures (e.g., hand lotion or cream), and even the frequent wearing of latex gloves. Allergic reactions have been reported for several antiseptic agents (e.g., quaternary ammonium compounds, iodine and iodophors, chlorhexidine, and others). Allergic reactions might also be due to an impurity or to some ingredient of the formulation (such as fragrances, or benzyl-, (iso)stearyl-, or myristyl-alcohol, phenoxyethanol, propylene glycol, parabens, or benzalkonium chloride) [37].

Alcohol-based formulations are generally better tolerated, but frequent use can lead to drying of skin, with negative influence on compliance. The addition of emollients, humectants, or other skin-conditioning agent reduces the problem of drying somewhat. Alcohol-based products that contain emollients generally cause significantly less skin irritation and drying than do plain or antimicrobial soap [34]. A negative aspect of alcohol-based formulations in particular is that they sting upon application to broken skin (cuts, abrasions, etc.).

\section{Factors That Impede Compliance}

The human factors that negatively affect adherence to good hand-hygiene practice were reviewed by Boyce \& Pittet (2002) [4]. Influences include the type of training of the healthcare provider (e.g., physician $v s$ nurse, etc.), type of hospital ward (e.g., intensive care vs medicine, etc.), time of day and day of the week (weekday $v s$ weekend), and the intensity of patient care (number of hand washings per hour) [4]. Some practical impediments include: dryness and irritation of skin caused by the handwashing agents, inconvenient location of the wash station or supplies, insufficient time due to understaffing or scheduling issues, concern that it interferes with the professional-patient relationship, over-reliance on gloves, or even skepticism or disagreement with policy recommendations. Also important are the institution's demonstrated level of interest in, promotion of, and support of good practice, and good example by co-workers (adherence to guidelines) [4]. 
Human factors include not only the healthcare professional's innate behavioral predilections, but also the institutional influences on that behavior. That is why efforts to employ behavioral theories to design more successful interventions stressed the importance of the complex interplay between individual and institutional factors [38]. As summarized by Boyce and Pittet (2002) [4]:

"Thus, the interdependence of individual factors, environmental constraints, and the institutional climate must be taken into account in the strategic planning and development of hand-hygiene campaigns. Interventions to promote hand hygiene in hospitals should consider variables at all these levels. Various factors involved in hand-hygiene behavior include intention, attitude towards the behavior, perceived social norm, perceived behavioral control, perceived risk for infection, hand-hygiene practices, perceived role model, perceived knowledge, and motivation. The factors necessary for change include 1) dissatisfaction with the current situation, 2) perception of alternatives, and 3) recognition, both at the individual and institutional level, of the ability and potential to change. Although the latter implies education and motivation, the former two necessitate a system change."

\section{Countermeasures}

\subsection{Education and Compliance Campaigns}

Education and campaigns employing multimodal approaches consistently show improvements in compliance with good hand hygiene practice, but disappointingly, only to a modest extent. Two studies, more than a decade apart but with similar results, provide representative examples. Pittet et al. (2000) [13] report the results of the implementation of a hospital-wide campaign to improve hand hygiene compliance and effectiveness, placing special emphasis on the increased use of alcohol-based handwipes ( $v s$ washing with soap and water). The three-year campaign produced a sustained increase in hand hygiene compliance, with a corresponding reduction in nosocomial infections. However, the improvement in compliance rate was modest, from $48 \%$ at the outset to $66 \%$ at the conclusion of the study. Chavali et al. (2014) [39] initiated an aggressive multimodal intervention to improve hand hygiene compliance among healthcare workers in the ICU of a tertiary care hospital in India. After one year, compliance had increased, but to an overall rate of only $78 \%$.

The potential for attaining super-high hand hygiene compliance rates by implementing an intensive program was recently demonstrated by Sickbert-Bennett et al. (2016) [40]. By asking all healthcare personnel in the hospital, including nutrition and food services staff, to observe and provide feedback on the hand hygiene compliance of each other, the compliance over a 17-month period improved from an already high level of more than $80 \%$ to an exceedingly high level of greater than $95 \%$. Surveys continue to reveal, however, that compliance rates this high are still the exception rather than the rule (Figure 2) [41] [42] [43]. 


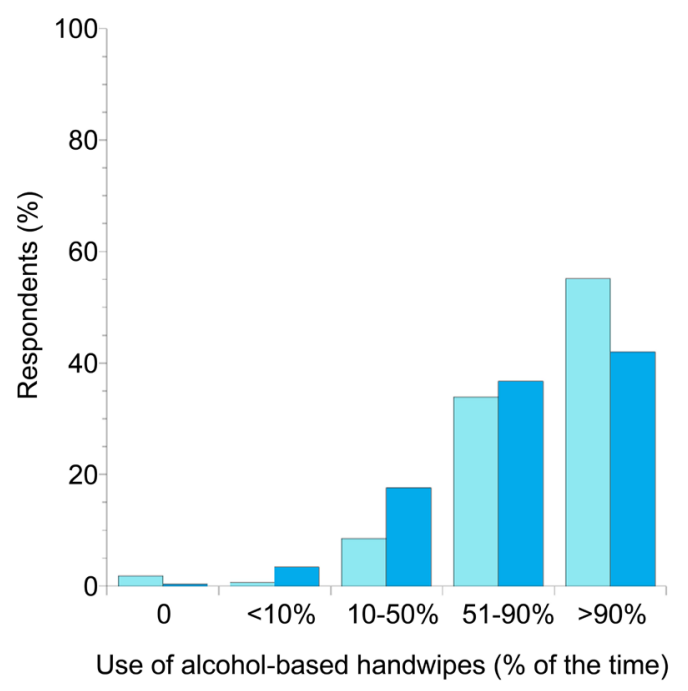

Figure 2. The hand hygiene practices of nurses in a large teaching hospital sampled in 2007 (left column of each study) and again in 2015 (right column of each study). Compliance was assessed as the $\%$ responders who used alcohol-based handwipes $0,<10 \%$, $10 \%-50 \%, 51 \%-90 \%$, or $>90 \%$ of the time. The figure was created from tabular data reported in Kingston et al. (2017) [42], with permission.

\subsection{Convenience of Placement}

Kirk et al. (2016) [12] reported that healthcare providers both in the United States and in Canada identified the same impediments to better hand hygiene compliance. In particular, more than half of the survey respondents indicated that they would exercise better hand hygiene compliance if alcohol-based handwipes were located closer to the patient. A relationship between location and accessibility of hand hygiene products and good hand hygiene practice has also been reported by others [44] [54].

\subsection{Counterintuitive Considerations}

It seems intuitive that the wearing of gloves for all interactions with patients would decrease, or even eliminate, the need for better hand hygiene compliance. However, washing gloves does not remove pathogens, and bacteria can penetrate small unnoticed holes in gloves and contaminate healthcare providers' hands [55]. Therefore, hand hygiene is necessary even after removing gloves. But because proper hand hygiene is a little less convenient when gloving is required, the use of gloves has been found, surprisingly, to be a risk factor for poor hand hygiene [56] [57] [58] [59] [60]. The wearing of gloves has also been found to give a false sense of security [61]. Cusini et al. (2015) [62] actually implemented a policy that eliminated mandatory gloving (contrary to WHO and CDC guidelines) in order to examine the effect on hand hygiene practice. They found that eliminating mandatory glove use increased hand hygiene compliance. Although this counterintuitive finding is not a universal finding [63] [64] [65] [66], it highlights the important influence of "human factors" in preventing better compliance. 


\section{Summary and Conclusion}

Although good hand hygiene is an accepted and recommended means of preventing healthcare-associated infections [12] [13] [67] [68] [69] [70], and despite early improvements, compliance rates have plateaued at levels that are disappointingly low ( $\leq 50 \%$ in some circumstances) [25] [32] [41] [71]. We previously highlighted some biological and treatment hurdles that impede better compliance [9]. But key drivers of low hand-hygiene compliance may well be more behavioral and operational than technical/scientific or procedural. Given that HAIs are inherently linked to healthcare workers' behavior (e.g. sub-optimal hand hygiene practices) there are also some human-factor hurdles, reviewed here. Intensive, facility-wide hand hygiene improvement programs work, but they are not always realistic or sustainable in all facilities. Fortunately, the human factors offer the best opportunity for significant improvement and better control of healthcare-associated infections. Anything that increases convenience (e.g., optimal placement of wash stations or handwipes), saves time, or decreases negative experience (e.g., skin irritation and dryness) significantly improves compliance. Better procedures and/or devices are needed that increase convenience, save time, or decrease negative experience. Hand hygiene is not a medical solution, but a supporting activity that is prone to variability due to several factors identified in various compliance studies. While compliance programs address the medical benefits of hand hygiene, they do not emphasise the holistic behavioral safety mindset required to effect safe, consistent hand hygiene; e.g., ensuring maintenance staff keep dispensers that are functioning and full, medical staff alerting their colleagues when a needed hand-hygiene event is missed or improperly done, etc. For these to happen consistently, the entire enterprise needs to be steeped in a safety culture based on strong hand-hygiene principles.

\section{Acknowledgements}

Members of the Delta Faucet Co. Medical Advisory Group (Robert Lubitz, Sanjib Chouduri, John Leslie, Brian Leon, Jay Ramasamy, Amy Beth Kresse, Kalib Alexander, Garry Marty, John Noble, Patrick Jonte)-for contributions to the development of the device. NEMA Research Inc. received funding from the Delta Faucet Co. to write this manuscript. The content is solely that of the authors.

\section{Conflicts of Interest}

The authors declare no conflicts of interest regarding the publication of this paper.

\section{References}

[1] WHO (2018) The Burden of Health Care-Associated Infection Worldwide: A Summary. http://www.who.int/gpsc/country_work/summary_20100430_en.pdf

[2] Bates, D.W., Larizgoitia, I., Prasopa-Plaizier, N. and Jha, A.K. (2009) Research Priority Setting Working Group of the WHO WAfPS. Global Priorities for Patient 
Safety Research. BMJ, 338, b1775. https://doi.org/10.1136/bmj.b1775

[3] Magill, S.S., Edwards, J.R., Bamberg, W., et al. (2014) Multistate Point-Prevalence Survey of Health Care-Associated Infections. The New England Journal of Medicine, 370, 1198-1208. https://doi.org/10.1056/NEJMoa1306801

[4] Boyce, J.M., Pittet, D. and Healthcare Infection Control Practices Advisory C, Force HSAIHHT (2002) Guideline for Hand Hygiene in Health-Care Settings. Recommendations of the Healthcare Infection Control Practices Advisory Committee and the HICPAC/SHEA/APIC/IDSA Hand Hygiene Task Force. Society for Healthcare Epidemiology of America/Association for Professionals in Infection Control/Infectious Diseases Society of America. MMWR Recommendations and Reports, 51, 1-45, quiz CE41-44. https://doi.org/10.1067/mic.2002.130391

[5] World Health Organization (2011) Report on the Burden of Endemic Health Care-Associated Infection Worldwide. World Health Organization, Geneva.

[6] European Centre for Disease Prevention and Control (2008) Annual Epidemiological Report on Communicable Diseases in Europe 2008. Report on the State of Communicable Diseases in the EU and EEA/EFTA Countries. European Centre for Disease Prevention and Control, Stockholm.

[7] Gordts, B., Vrijens, F., Hulstaert, F., Devriese, S. and Van de Sande, S. (2010) The 2007 Belgian National Prevalence Survey for Hospital-Acquired Infections. Journal of Hospital Infection, 75, 163-167. https://doi.org/10.1016/j.jhin.2010.01.006

[8] Klevens, R.M., Edwards, J.R., Richards Jr., C.L., et al. (2007) Estimating Health Care-Associated Infections and Deaths in U.S. Hospitals, 2002. Public Health Reports, 122, 160-166. https://doi.org/10.1177/003335490712200205

[9] Pergolizzi, J.V.J., Raffa, R.B. and Taylor, R.J. Persistence of Healthcare-Associated (Nosocomial) Infections Due to Inadequate Hand Hygiene: Part 1-Biological and Treatment Factors. Journal of Clinical Pharmacy and Therapeutics, Submitted for Publication.

[10] Stone, P.W. (2009) Economic Burden of Healthcare-Associated Infections: An American Perspective. Expert Review of Pharmacoeconomics \& Outcomes Research, 9, 417-422. https://doi.org/10.1586/erp.09.53

[11] Casewell, M. and Phillips, I. (1977) Hands as Route of Transmission for Klebsiella Species. British Medical Journal, 2, 1315-1317. https://doi.org/10.1136/bmj.2.6098.1315

[12] Kirk, J., Kendall, A., Marx, J.F., et al. (2016) Point of Care Hand Hygiene-Where's the Rub? A Survey of US and Canadian Health Care Workers' Knowledge, Attitudes, and Practices. American Journal of Infection Control, 44, 1095-1101. https://doi.org/10.1016/j.ajic.2016.03.005

[13] Pittet, D., Hugonnet, S., Harbarth, S., et al. (2000) Effectiveness of a Hospital-Wide Programme to Improve Compliance with Hand Hygiene. Infection Control Programme. Lancet, 356, 1307-1312. https://doi.org/10.1016/S0140-6736(00)02814-2

[14] Ehrenkranz, N.J. and Alfonso, B.C. (1991) Failure of Bland Soap Handwash to Prevent Hand Transfer of Patient Bacteria to Urethral Catheters. Infection Control \& Hospital Epidemiology, 12, 654-662. https://doi.org/10.2307/30146898

[15] Sartor, C., Jacomo, V., Duvivier, C., Tissot-Dupont, H., Sambuc, R. and Drancourt, M. (2000) Nosocomial Serratia Marcescens Infections Associated with Extrinsic Contamination of a Liquid Nonmedicated Soap. Infection Control \& Hospital Epidemiology, 21, 196-199. https://doi.org/10.1086/501743

[16] Larson, E.L. and Morton, H.E. (1991) Alcohols. In: Block, S.S., Ed., Disinfection, Sterilization and Preservation, 4th Edition, Lea and Febiger, Philadelphia, 642-654. 
[17] Jones, M.V., Rowe, G.B., Jackson, B. and Pritchard, N.J. (1986) The Use of Alcoholic Paper Wipes for Routine Hand Cleansing: Results of Trials in Two Hospitals. Journal of Hospital Infection, 8, 268-274. https://doi.org/10.1016/0195-6701(86)90123-4

[18] Butz, A.M., Laughon, B.E., Gullette, D.L. and Larson, E.L. (1990) Alcohol-Impregnated Wipes as an Alternative in Hand Hygiene. American Journal of Infection Control, 18, 70-76. https://doi.org/10.1016/0196-6553(90)90084-6

[19] Mortimer, E.A., Lipsitz, P.J., Wolinsky, E., Gonzaga, A.J. and Rammelkamp, C.H. (1962) Transmission of Staphylococci between Newborns. Importance of the Hands to Personnel. American Journal of Diseases of Children, 104, 289-295. https://doi.org/10.1001/archpedi.1962.02080030291012

[20] Larson, E. (1988) A Causal Link between Handwashing and Risk of Infection? Examination of the Evidence. Infection Control \& Hospital Epidemiology, 9, 28-36. https://doi.org/10.2307/30144131

[21] Larson, E. (1999) Skin Hygiene and Infection Prevention: More of the Same or Different Approaches? Clinical Infectious Diseases, 29, 1287-1294. https://doi.org/10.1086/313468

[22] Doebbeling, B.N., Stanley, G.L., Sheetz, C.T., et al. (1992) Comparative Efficacy of Alternative Hand-Washing Agents in Reducing Nosocomial Infections in Intensive Care Units. The New England Journal of Medicine, 327, 88-93. https://doi.org/10.1056/NEJM199207093270205

[23] Zafar, A.B., Butler, R.C., Reese, D.J., Gaydos, L.A. and Mennonna, P.A. (1995) Use of $0.3 \%$ Triclosan (Bacti-Stat) to Eradicate an Outbreak of Methicillin-Resistant Staphylococcus aureus in a Neonatal Nursery. American Journal of Infection Control, 23, 200-208. https://doi.org/10.1016/0196-6553(95)90042-X

[24] Webster, J., Faoagali, J.L. and Cartwright, D. (1994) Elimination of Methicillin-Resistant Staphylococcus aureus from a Neonatal Intensive Care Unit after Hand Washing with Triclosan. Journal of Paediatrics and Child Health, 30, 59-64. https://doi.org/10.1111/j.1440-1754.1994.tb00568.x

[25] Allegranzi, B. and Pittet, D. (2009) Role of Hand Hygiene in Healthcare-Associated Infection Prevention. Journal of Hospital Infection, 73, 305-315.

https://doi.org/10.1016/j.jhin.2009.04.019

[26] Hocine, M.N. and Temime, L. (2015) Impact of Hand Hygiene on the Infectious Risk in Nursing Home Residents: A Systematic Review. American Journal of Infection Control, 43, e47-e52.

[27] Larson, E.L., Early, E., Cloonan, P., Sugrue, S. and Parides, M. (2000) An Organizational Climate Intervention Associated with Increased Handwashing and Decreased Nosocomial Infections. Behavioral Medicine, 26, 14-22. https://doi.org/10.1080/08964280009595749

[28] Bryan, J.L., Cohran, J. and Larson, E.L. (1995) Hand Washing: A Ritual Revisited. Critical Care Nursing Clinics of North America, 7, 617-625. https://doi.org/10.1016/S0899-5885(18)30354-X

[29] Pittet, D., Mourouga, P. and Perneger, T.V. (1999) Compliance with Handwashing in a Teaching Hospital. Infection Control Program. Annals of Internal Medicine, 130, 126-130. https://doi.org/10.7326/0003-4819-130-2-199901190-00006

[30] Avila-Aguero, M.L., Umana, M.A., Jimenez, A.L., Faingezicht, I. and Paris, M.M. (1998) Handwashing Practices in a Tertiary-Care, Pediatric Hospital and the Effect on an Educational Program. Clinical Performance and Quality Healthcare, 6, 70-72.

[31] Larson, E. and Kretzer, E.K. (1995) Compliance with Handwashing and Barrier 
Precautions. Journal of Hospital Infection, 30, 88-106.

[32] Kingston, L., O’Connell, N.H. and Dunne, C.P. (2016) Hand Hygiene-Related Clinical Trials Reported since 2010: A Systematic Review. Journal of Hospital Infection, 92, 309-320. https://doi.org/10.1016/j.jhin.2015.11.012

[33] Larson, E., Friedman, C., Cohran, J., Treston-Aurand, J. and Green, S. (1997) Prevalence and Correlates of Skin Damage on the Hands of Nurses. Heart \& Lung, 26, 404-412. https://doi.org/10.1016/S0147-9563(97)90027-3

[34] Boyce, J.M., Kelliher, S. and Vallande, N. (2000) Skin Irritation and Dryness Associated with Two Hand-Hygiene Regimens: Soap-and-Water Hand Washing versus Hand Antisepsis with an Alcoholic Hand Gel. Infection Control \& Hospital Epidemiology, 21, 442-448. https://doi.org/10.1086/501785

[35] Larson, E.L., Hughes, C.A., Pyrek, J.D., Sparks, S.M., Cagatay, E.U. and Bartkus, J.M. (1998) Changes in Bacterial Flora Associated with Skin Damage on Hands of Health Care Personnel. American Journal of Infection Control, 26, 513-521. https://doi.org/10.1016/S0196-6553(98)70025-2

[36] Ojajärvi, J., Mäkelä, P. and Rantasalo, I. (1977) Failure of Hand Disinfection with Frequent Hand Washing: A Need for Prolonged Field Studies. Journal of Hygiene, 79, 107-119. https://doi.org/10.1017/S0022172400052906

[37] Ophaswongse, S. and Maibach, H.I. (1994) Alcohol Dermatitis: Allergic Contact Dermatitis and Contact Urticaria Syndrome. A Review. Contact Dermatitis, 30, 1-6. https://doi.org/10.1111/j.1600-0536.1994.tb00719.x

[38] Kretzer, E.K. and Larson, E.L. (1998) Behavioral Interventions to Improve Infection Control Practices. American Journal of Infection Control, 26, 245-253. https://doi.org/10.1016/S0196-6553(98)80008-4

[39] Chavali, S., Menon, V. and Shukla, U. (2014) Hand Hygiene Compliance among Healthcare Workers in an Accredited Tertiary Care Hospital. Indian Journal of Critical Care Medicine, 18, 689-693. https://doi.org/10.4103/0972-5229.142179

[40] Sickbert-Bennett, E.E., DiBiase, L.M., Willis, T.M., Wolak, E.S., Weber, D.J. and Rutala, W.A. (2016) Reduction of Healthcare-Associated Infections by Exceeding High Compliance with Hand Hygiene Practices. Emerging Infectious Diseases, 22, 1628-1630. https://doi.org/10.3201/eid2209.151440

[41] McGuckin, M., Waterman, R. and Govednik, J. (2009) Hand Hygiene Compliance Rates in the United States-A One-Year Multicenter Collaboration Using Product/Volume Usage Measurement and Feedback. American Journal of Medical Quality, 24, 205-213. https://doi.org/10.1177/1062860609332369

[42] Kingston, L.M., Slevin, B.L., O’Connell, N.H. and Dunne, C.P. (2017) Hand Hygiene: Attitudes and Practices of Nurses, a Comparison between 2007 and 2015. American Journal of Infection Control, 45, 1300-1307. https://doi.org/10.1016/j.ajic.2017.08.040

[43] Akanji, J., Walker, J. and Christian, R. (2017) Effectiveness of Formal Hand Hygiene Education and Feedback on Healthcare Workers' Hand Hygiene Compliance and Hospital-Associated Infections in Adult Intensive Care Units: A Systematic Review Protocol. JBI Database of Systematic Reviews and Implementation Reports, 15, 1272-1279. https://doi.org/10.11124/JBISRIR-2016-003019

[44] Stackelroth, J., Sinnott, M. and Shaban, R.Z. (2015) Hesitation and Error: Does Product Placement in an Emergency Department Influence Hand Hygiene Performance? American Journal of Infection Control, 43, 913-916. https://doi.org/10.1016/j.ajic.2015.04.199 
[45] Gould, D.J., Moralejo, D., Drey, N. and Chudleigh, J.H. (2010) Interventions to Improve Hand Hygiene Compliance in Patient Care. The Cochrane Database of Systematic Reviews, No. 9, CD005186.

[46] Whitby, M., Pessoa-Silva, C.L., McLaws, M.L., et al. (2007) Behavioural Considerations for Hand Hygiene Practices: The Basic Building Blocks. Journal of Hospital Infection, 65, 1-8. https://doi.org/10.1016/j.jhin.2006.09.026

[47] Chou, T., Kerridge, J., Kulkarni, M., Wickman, K. and Malow, J. (2010) Changing the Culture of Hand Hygiene Compliance Using a Bundle That Includes a Violation Letter. American Journal of Infection Control, 38, 575-578. https://doi.org/10.1016/j.ajic.2010.01.016

[48] Moret, L., Tequi, B. and Lombrail, P. (2004) Should Self-Assessment Methods Be Used to Measure Compliance with Handwashing Recommendations? A Study Carried out in a French University Hospital. American Journal of Infection Control, 32, 384-390. https://doi.org/10.1016/j.ajic.2004.02.004

[49] Bischoff, W.E., Reynolds, T.M., Sessler, C.N., Edmond, M.B. and Wenzel, R.P. (2000) Handwashing Compliance by Health Care Workers: The Impact of Introducing an Accessible, Alcohol-Based Hand Antiseptic. Archives of Internal Medicine, 160, 1017-1021. https://doi.org/10.1001/archinte.160.7.1017

[50] Cure, L. and Van Enk, R. (2015) Effect of Hand Sanitizer Location on Hand Hygiene Compliance. American Journal of Infection Control, 43, 917-921. https://doi.org/10.1016/j.ajic.2015.05.013

[51] Azlz, A.M. (2013) How Better Availability of Materials Improved Hand-Hygiene Compliance. British Journal of Nursing, 22, 460-453.

[52] Maury, E., Alzieu, M., Baudel, J.L., et al. (2000) Availability of an Alcohol Solution Can Improve Hand Disinfection Compliance in an Intensive Care Unit. American Journal of Respiratory and Critical Care Medicine, 162, 324-327. https://doi.org/10.1164/ajrccm.162.1.9908118

[53] Pittet, D. (2001) Compliance with Hand Disinfection and Its Impact on Hospital-Acquired Infections. Journal of Hospital Infection, 48, S40-S46.

[54] Thomas, K. (2012) Hospitals Get Aggressive, and Infections Plunge. Hospitals \& Health Networks, 86, 32-36.

[55] Doebbeling, B.N., Pfaller, M.A., Houston, A.K. and Wenzel, R.P. (1988) Removal of Nosocomial Pathogens from the Contaminated Glove. Implications for Glove Reuse and Handwashing. Annals of Internal Medicine, 109, 394-398. https://doi.org/10.7326/0003-4819-109-5-394

[56] Fuller, C., Savage, J., Besser, S., et al. (2011) The Dirty Hand in the Latex Glove: A Study of Hand Hygiene Compliance When Gloves Are Worn. Infection Control \& Hospital Epidemiology, 32, 1194-1199. https://doi.org/10.1086/662619

[57] Thompson, B.L., Dwyer, D.M., Ussery, X.T., Denman, S., Vacek, P. and Schwartz, B. (1997) Handwashing and Glove Use in a Long-Term-Care Facility. Infection Control \& Hospital Epidemiology, 18, 97-103. https://doi.org/10.2307/30142397

[58] Eveillard, M., Joly-Guillou, M.L. and Brunel, P. (2012) Correlation between Glove Use Practices and Compliance with Hand Hygiene in a Multicenter Study with Elderly Patients. American Journal of Infection Control, 40, 387-388. https://doi.org/10.1016/j.ajic.2011.05.008

[59] Katherason, S.G., Naing, L., Jaalam, K., et al. (2010) Hand Decontamination Practices and the Appropriate Use of Gloves in Two Adult Intensive Care Units in Malaysia. The Journal of Infection in Developing Countries, 4, 118-123. https://doi.org/10.3855/jidc.593 
[60] Girou, E., Chai, S.H., Oppein, F., et al. (2004) Misuse of Gloves: The Foundation for Poor Compliance with Hand Hygiene and Potential for Microbial Transmission? Journal of Hospital Infection, 57, 162-169. https://doi.org/10.1016/j.jhin.2004.03.010

[61] Jang, J.H., Wu, S., Kirzner, D., et al. (2010) Focus Group Study of Hand Hygiene Practice among Healthcare Workers in a Teaching Hospital in Toronto, Canada. Infection Control \& Hospital Epidemiology, 31, 144-150. https://doi.org/10.1086/649792

[62] Cusini, A., Nydegger, D., Kaspar, T., Schweiger, A., Kuhn, R. and Marschall, J. (2015) Improved Hand Hygiene Compliance after Eliminating Mandatory Glove Use from Contact Precautions-Is Less More? American Journal of Infection Control, 43, 922-927. https://doi.org/10.1016/j.ajic.2015.05.019

[63] Kim, P.W., Roghmann, M.C., Perencevich, E.N. and Harris, A.D. (2003) Rates of Hand Disinfection Associated with Glove Use, Patient Isolation, and Changes between Exposure to Various Body Sites. American Journal of Infection Control, 31, 97-103. https://doi.org/10.1067/mic.2003.32

[64] Lund, S., Jackson, J., Leggett, J., Hales, L., Dworkin, R. and Gilbert, D. (1994) Reality of Glove Use and Handwashing in a Community Hospital. American Journal of Infection Control, 22, 352-357. https://doi.org/10.1016/0196-6553(94)90034-5

[65] Lankford, M.G., Zembower, T.R., Trick, W.E., Hacek, D.M., Noskin, G.A. and Peterson, L.R. (2003) Influence of Role Models and Hospital Design on Hand Hygiene of Healthcare Workers. Emerging Infectious Diseases, 9, 217-223. https://doi.org/10.3201/eid0902.020249

[66] Eveillard, M., Guilloteau, V., Kempf, M., et al. (2011) Impact of Improving Glove Usage on the Hand Hygiene Compliance. American Journal of Infection Control, 39, 608-610. https://doi.org/10.1016/j.ajic.2010.08.022

[67] Rosenthal, V.D., Guzman, S. and Safdar, N. (2005) Reduction in Nosocomial Infection with Improved Hand Hygiene in Intensive Care Units of a Tertiary Care Hospital in Argentina. American Journal of Infection Control, 33, 392-397. https://doi.org/10.1016/j.ajic.2004.08.009

[68] Mathai, E., Allegranzi, B., Seto, W.H., et al. (2010) Educating Healthcare Workers to Optimal Hand Hygiene Practices: Addressing the Need. Infection, 38, 349-356. https://doi.org/10.1007/s15010-010-0047-7

[69] Maas, A., Flament, P., Pardou, A., Deplano, A., Dramaix, M. and Struelens, M.J. (1998) Central Venous Catheter-Related Bacteraemia in Critically Ill Neonates: Risk Factors and Impact of a Prevention Programme. Journal of Hospital Infection, 40, 211-224. https://doi.org/10.1016/S0195-6701(98)90139-6

[70] Ofek Shlomai, N., Rao, S. and Patole, S. (2015) Efficacy of Interventions to Improve Hand Hygiene Compliance in Neonatal Units: A Systematic Review and Meta-Analysis. European Journal of Clinical Microbiology \& Infectious Diseases, 34, 887-897. https://doi.org/10.1007/s10096-015-2313-1

[71] Allegranzi, B., Conway, L., Larson, E. and Pittet, D. (2014) Status of the Implementation of the World Health Organization Multimodal Hand Hygiene Strategy in United States of America Health Care Facilities. American Journal of Infection Control, 42, 224-230. https://doi.org/10.1016/j.ajic.2013.11.015 